\title{
PENGUKURAN KEPUASAN PESERTA JKN MELALUI PENDEKATAN IMPORTANCE-PERFORMANCE ANALYSIS
}

\author{
Dina Lusianti \\ Fakultas Ekonomi Universitas Muria Kudus \\ Email: dina.lusianti@umk.ac.id
}

\begin{abstract}
Abstrak
Peogram Jaminan Kesehatan Nasional (JKN) yang diselenggarakan oleh BPJS Kesehatan menerapkan sistem kendali mutu dan kendali biaya. Pelayanan yang diberikan diharapkan dapat memberikan jaminan kesehatan bagi seluruh rakyat Indonesia. Tidak hanya kepastian jaminan, BPJS Kesehatan senantiasa berupaya menempatkan kepuasan Peserta JKN sebagai salah satu kinerja yang harus terus ditingkatkan. Sebagai upaya peningkatan kepuasan Peserta maka dilakukan pendekatan melalui Importance-Performance Analysis (IPA). Melalui pendekatan IPA dapat diketahui besaran indeks kepuasan Peserta sekaligus analisa mengenai atribut yang membutuhkan penanganan lebih lanjut guna meningkatkan kepuasan Peserta JKN. Diperoleh indeks kepuasan Peserta JKN Cabang Pati pada hal layanan administrasi sebesar 88,85 persen. Adapun atribut yang perlu ditingkatkan adalah mengenai jaminan waktu apabila terdapat kendala aplikasi karena adanya maintenance maupun perbaikan lainnya.
\end{abstract}

Kata Kunci : Kepuasan, JKN, IPA

\section{A. PENDAhUlUAN}

Semenjak diberlakukannya Undang-undang Nomor 40 tahun 2004 tentang Sistem Jaminan Sosial Nasional (SJSN) maka Pemerintah senantiasa mewujudkan hak atas jaminan sosial bagi setiap penduduknya. Bentuk jaminan sosial yang diberikan antara lain adalah mengenai jaminan kesehatan. Jaminan kesehatan ini selanjutnya disebut sebagai Jaminan Kesehatan Nasional (JKN).

JKN diselenggarakan oleh Badan Penyelanggara Jaminan Sosial (BPJS) Kesehatan semenjak 1 Januari 2014 seperti yang termaktub dalam Undang-undang Nomor 24 tahun 2011. Sebagai bentuk transformasi dari PT Askes (Persero), BPJS Kesehatan merupakan badan penyelenggara yang berbentuk badan hukum berdasarkan prinsip kegotongroyongan, nirlaba, keterbukaan, kehati-hatian, akuntabilitas, portabilitas, kepesertaan bersifat wajib, dana amanat, dan hasil pengelolaan dana jaminan sosial seluruhnya untuk pengembangan program dan untuk sebesar-besarnya kepentingan peserta (Edris dan Dina, 2016). 
BPJS Kesehatan di dalam operasionalisasinya wajib melakukan berbagai pengembangan program baik secara preventif maupun kuratif. Semua ini bermuara pada tujuan untuk melayani peserta dengan baik sesuai dengan prinsip managed care. Yakni pemberian pelayanan kesehatan bermutu denga asas manfaat kendali biaya.

Meskipun penyelenggaraan program JKN dengan kendali biaya bukan berarti mengesampingkan kualitas pelayanannya. Program JKN yang diselenggarakan oleh BPJS Kesehatan juga menjadikan ukuran kepuasan peserta sebagai tolak ukur kinerja BPJS Kesehatan. Oleh karenanya kepuasan peserta JKN menjadi perhatian khusus bagi BPJS Kesehatan. Berikut testimoni dari Peserta JKN.

Mengucapkan terima kasih kepada Pemerintah yang mencanangkan program JKN, BPJS Kesehatan yang menyelenggarakan dengan baik dan Fasilitas kesehatan yang telah melayani dengan baik pula (I Putu Mantono, 2016, dalam http://bpjskesehatancabangklungkung.blogspot.co.id/).

"Selama saya mengikuti prosedur rujukan, tidak pernah ada iur biaya kemoterapi sekali pun dari tahun 2014 sampai sekarang (2016). Padahal setahu saya, biaya kemoterapi di kelas I bisa mencapai sekitar Rp 12 juta untuk sekali kemoterapi. Ke depannya semoga pelayanan BPJS Kesehatan untuk pesertanya bisa ditingkatkan, khususnya di rumah sakit, agar kita bisa lebih optimal memperoleh pelayanan kesehatan (Ardiani, 2016, dalam Kompasiana).

Banyak peserta JKN yang merasa tertolong atas keberadaan program JKN yang diselenggarakan oleh BPJS Kesehatan ini. Para peserta tidak perlu memikirkan biaya pengobatan sehingga dapat fokus pada proses pengobatan dan penyembuhan. Peserta juga tidak perlu khawatir untuk menjadi Sadikin (sakit jadi miskin).

Meskipun BPJS Kesehatan telah memberikan pelayanan prima, masih ada peserta yang menyampaikan keluhannya terkait jaminan pelayanan kesehatannya. Berikut merupakan ulasannya.

"Sebagian besar peserta BPJS mengeluhkan pelayanan yang diberikan rumah sakit. Keluhan itu antara lain meliputi kekurangan kamar rawat inap yang menyebabkan banyak pasien ditolak rumah sakit dan pendataaan penerima bayar iuran (PBI) di tingkat kabupaten kota/kabupaten dan provinsi yang tidak akurat, tidak transparan, dan tidak sesuai dengan kondisi lapangan.(Roni, 2015, dalam jateng.prof.go.id) 
Keluhan mengenai perbedaan pelayanan yang diberikan Rumah Sakit kepada pasien peserta BPJS dengan pasien non BPJS. "Diharapkan kedepan tidak ada lagi perbedaan tersebut. (Kapten (Purn) Karsidin, 2016 dalam murianews.com)

Kepuasan peserta merupakan tugas penting bagi BPJS Kesehatan. Oleh karenanya perlu dilakukan pengukuran terhadap kepuasan peserta JKN sebagai bentuk kinerja yang dilakukan oleh BPJS Kesehatan. Salah satu metode yang dapat digunakan untuk mengukur kepuasan adalah dengan melalui pendekatan ImportancePerformance Anaysis (IPA).

IPA merupakan metode pengukuran kepuasan pelanggan dengan melakukan analisa perbandingan kenyataan yang dirasakan oleh pelanggan dibandingkan dengan harapan pelanggan. Akumulasi dari jawaban pelanggan selanjutnya digambarkan dalam bentuk kuadran. Selanjutnya dilakukan analisa untuk masingmasing kuadrannya untuk mengidentifikasi tindakan yang perlu dilakukan.

\section{B. RUMUSAN MASALAH}

Mengingat pentingnya pengukuran kepuasan peserta JKN maka dapat dirumuskan suatu masalah yakni bagaimana analisa IPA dapat digunakan untuk mengukur kepuasan Peserta JKN sekaligus menentukan langkah-langkah sebagai upaya peningkatan pelayanan adminsitrasi kantor pada Peserta JKN di wilayah kerja BPJS Kesehatan Cabang Pati.

\section{TINJAUAN PUSTAKA}

\section{Kepuasan Pelanggan}

Kepuasan pelanggan adalah tingkat keadaan yang dirasakan seseorang yang merupakan hasil dari membandingkan penampilan atau outcome produk yang dirasakan dalam hubungannya dengan harapan seseorang (Kotler, 2007). Seorang peserta BPJS Kesehatan akan merasa puas apabila pelayanan yang telah dirasakan sama atau bahkan melebihi nilai harapan peserta. Sebaliknya peserta BPJS Kesehatan akan merasa tidak puas apabila pelayanan yang dirasakan tidak dapat memenuhi nilai harapan dari pelanggan.

Dalam rangka menciptakan kepuasan pelanggan, barang atau jasa yang ditawarkan sutu organisasi atau perusahaan harus berkualitas. Kualitas mencerminkan semua dimensi pelayanan yang menghasilkan manfaat (benefit) bagi 
pelanggan. Lebih lanjut konsep kepuasaan pelanggan memuat dua elemen yang mempengaruhi yaitu harapan dan kinerja. Kinerja adalah persepsi konsumen terhadap apa yang diterima setelah mengkonsumsi produk (barang atau jasa). Harapan adalah perkiraan konsumen tentang apa yang akan diterima apabila mengkonsumsi produk (barang atau jasa).

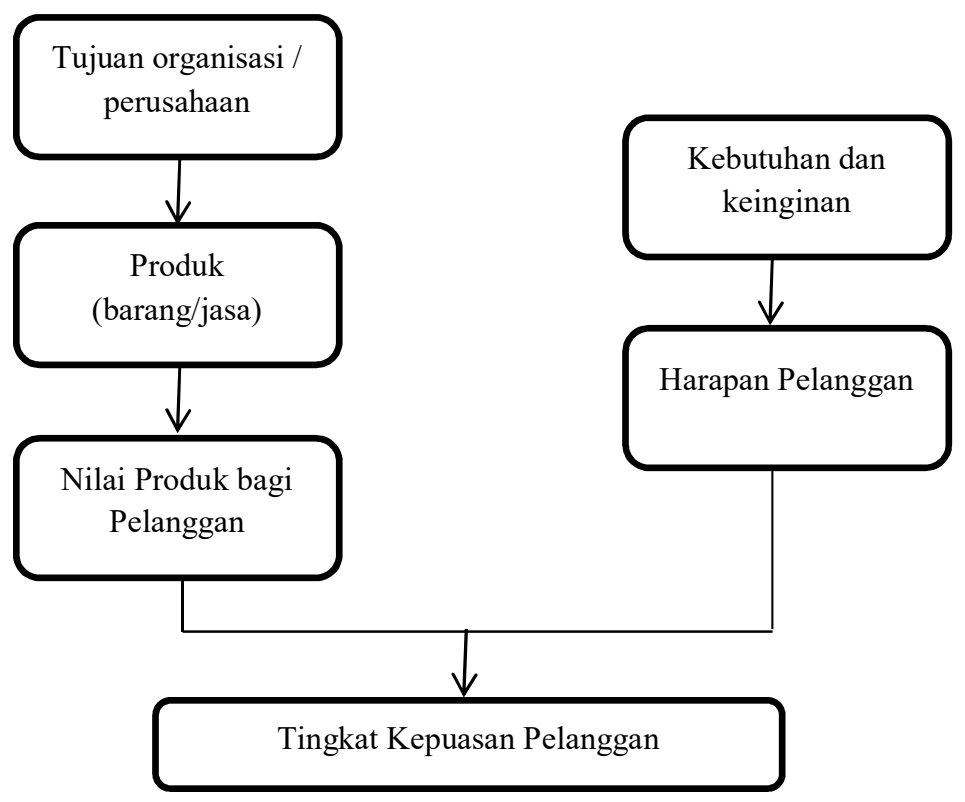

Gambar 1 Konsep Kepuasan Pelanggan

\section{Metode Importance-Performance Analysis}

Importance-Performance Analysis (IPA) dapat digunakan untuk menganalisa berbagai elemen dalam kualitas layanan serta mengidentifikasi tindakan yang diperlukan. Dengan penggunaan metode IPA akan diketahui seberapa besar pelanggan merasa puas terhadap kinerja perusahaan dan seberapa besar pihak penyedia jasa memahami apa yang diinginkan pelanggan terhadap jasa yang telah diberikan.

Sangat Tidak Memuaskan

\begin{tabular}{|c|c|}
\hline $\begin{array}{c}\text { Concentrate These } \\
(1)\end{array}$ & $\begin{array}{c}\text { Keep Up The Good Work } \\
(2)\end{array}$ \\
\hline $\begin{array}{c}\text { Low Priority } \\
(3)\end{array}$ & $\begin{array}{c}\text { Possible Overkill } \\
(4)\end{array}$ \\
\hline
\end{tabular}

Sangat Tidak Penting

Sangat Memuaskan 
Gambar 2 Kuadran Importance-Performance Analysis

Strategi yang dapat dilakukan berkenaan dengan posisi masing-masing variabel pada keempat kuadran tersebut :

1. Concentrate These

Kuadran pertama merupakan wilayah yang memuat faktor-faktor yang dianggap penting oleh pelanggan tetapi pada kenyataannya faktor-faktor ini belum sesuai dengan harapan pelanggan. Sehingga variabel yang berada dalam kuadaran ini perlu untuk ditingkatkan.

2. Keep Up The Good Work

Faktor-faktor yang dianggap penting oleh pelanggan dan telah dianggap sesuai dengan yang dirasakan oleh pelanggan berada pada kuadran kedua. Variabel yang masuk dalam kuadran keddua harus tetap dipertahankan karena semua variabel ini menciptakan keunggulan di mata pelanggan.

3. LowPriority

Kuadran ketiga memuat faktor-faktor yang dianggap kurang penting oleh pelanggan tetapi pada kenyataan kinerjanya tidak terlalu istimewa. Peningkatan variabel yang termasuk dalam kuadran ini dapat dipertimbangkan kembali karena pengaruhnya terhadap manfaat yang dirasakan oleh pelanggan sangat kecil.

4. Possible Overkill

Faktor-faktor yang dianggap kurang penting oleh pelanggan dan dirasakan terlalu berlebihan berada pada kuadran keempat. Sehingga variabel yang termasuk dalam kuadran ini dapat dikurangi intensitasnya sekaligus dapat menghemat biaya pelayanan.

\section{METODOLOGI}

Jenis penelitian ini merupakan penelitian lapangan yang bersifat kuantitatif. Sumber data berupa data primer dan data sekunder. Data primer diperoleh dengan melakukan wawancara dan observasi dengan menggunakan alat bantu kuesioner terhadap Peserta JKN yang telah memperoleh pelayanan administrasi di kantor Cabang Pati dalam kurun tiga bulan terakhir sebanyak 150 responden. Sedangkan data sekunder diperoleh melalui buku-buku, majalah, internet dan jurnal pendukung yang relevan. 
Analisis yang digunakan dengan pendekatan Importance-Performance Analysis (IPA). Langkah pertama adalah mengukur indeks kepuasan peserta (CSI). Yakni dengan membandingkan antara kinerja pelayanan yang telah dilakukan oleh BPJS Kesehatan Cabang Pati dengan harapan Peserta. Adapun atribut dalam penelitian ini terdapat 25 atribut dalam dimensi pelayanan yang meliputi emphaty, responsiveness, assurance, reliability, dan tangible. Dilanjutkan dengan analisa dari rekap jawaban responden sehingga dapat diketahui atribut apa yang perlu untuk ditingkatkan.

\section{E. HASIL DAN PEMBAHASAN}

Dalam penelitian ini diperoleh hasil bahwa dari 150 responden, sebanyak 63 persen berjenis kelamin Perempuan dan sisanya 37 persen berjenis kelamin Laki-laki. Mayoritas responden didominasi dengan status kepesertaan sebagai Peserta yakni sebanyak 72 persen. Sisanya sebanyak 31 berstatus sebagai Istri, 1 orang sebagai Suami dan 4 orang sebagai Anak.

Berdasarkan jenis kepesertaan karakteristik responden dapat terlihat pada tabel 1 dibawah ini.

\begin{tabular}{|c|c|c|}
\hline Jenis Kepesertaan & Jumlah & Persentase \\
\hline \hline Pekerja Penerima Upah (PPU) & 73 & 49 \\
\hline Pekerja Bukan Penerima Upah (PBPU) & 52 & 35 \\
\hline Penerima Bantuan Iuran (PBI) & 25 & 16 \\
\hline Total & $\mathbf{1 5 0}$ & $\mathbf{1 0 0}$ \\
\hline
\end{tabular}

Tabel 1 Karakteristik Responden Berdasarkan Jenis Kepesertaan

Dari rekap 150 responden yang telah menjawab pertanyaan dalam kuesioner sekaligus wawancara yang telah dilakukan maka diperoleh hasil bahwa indeks kepuasan Peserta JKN dalam hal administrasi pelayanan di Kantor Cabang sebesar 88,85 persen. Dengan rincian untuk masing-masing dimensi adalah sebagaimana tabel 2: 


\begin{tabular}{|l|c|}
\hline \multicolumn{1}{|c|}{ Dimensi } & CSI (\%) \\
\hline Emphaty & 88.53 \\
\hline Responsiveness & 89.37 \\
\hline Assurance & 86.71 \\
\hline Reliability & 88.23 \\
\hline Tangible & 91.40 \\
\hline
\end{tabular}

Tabel 2 Indeks Kepuasan Peserta JKN Cabang Pati

Merujuk pada pendekatan Importance-Performance Analysis diperoleh hasil bahwa banyak atribut yang telah dapat memuaskan Peserta JKN dan hal ini tetap dijaga agar Peserta tetap puas. Diantaranya adalah atribut mengenai keramahan petugas, kecepatan petugas dalam melayani dan kenyamana ruang tunggu pelayanan.

Namun demikian terdapat satu atribut yang dirasa masih belum memuaskan padahal dirasa sangat penting bagi para Peserta yakni mengenai Kemampuan petugas kantor BPJS Kesehatan dalam memberikan kepastian waktu saat aplikasi mengalami kendala.

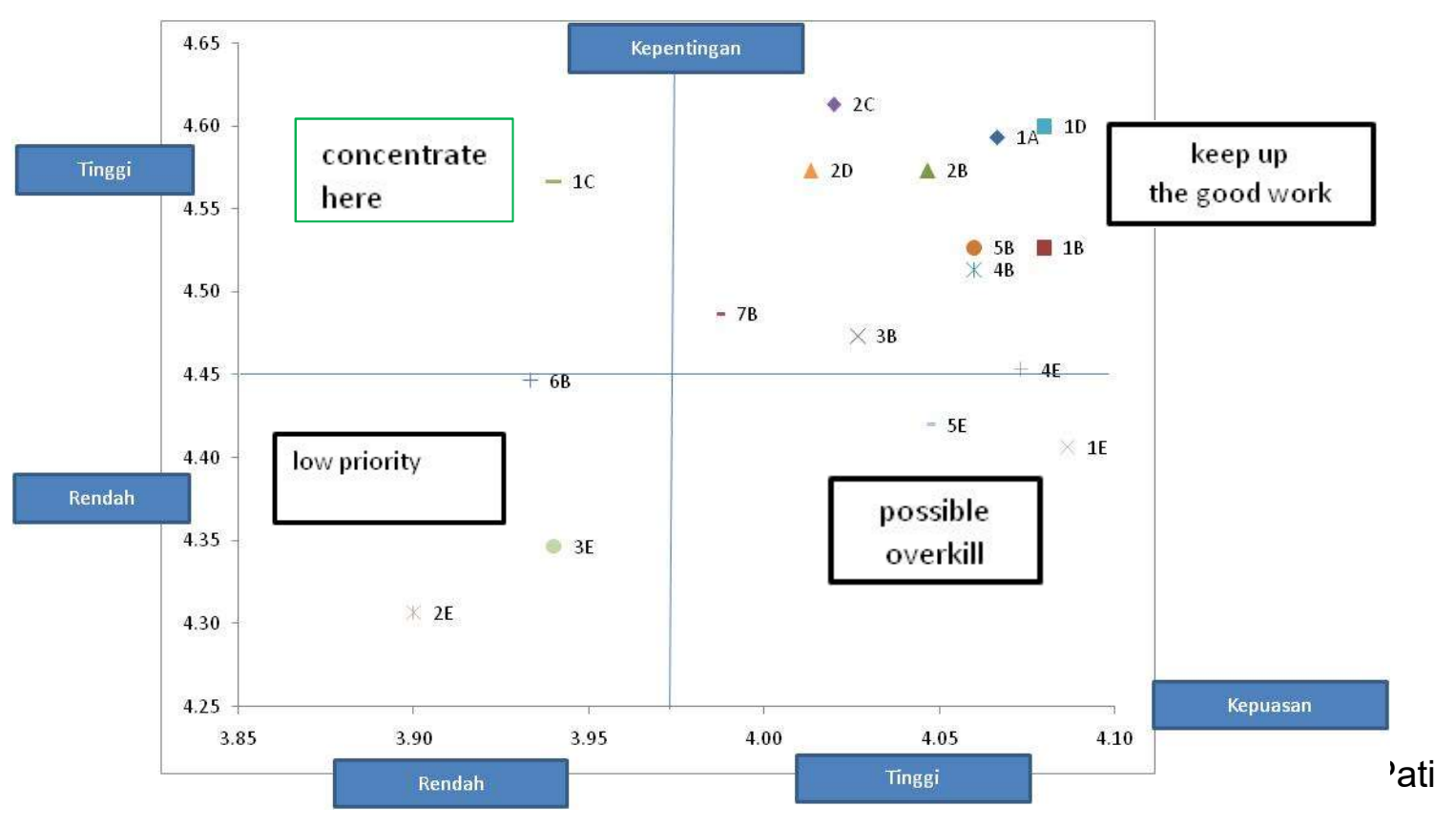




\section{F. SIMPULAN}

Pendekatan Importance-Performance Analysis (IPA) merupakan metode pengukuran kepuasan pelanggan dengan melakukan analisa perbandingan kenyataan yang dirasakan oleh pelanggan dibandingkan dengan harapan pelanggan. Akumulasi dari jawaban pelanggan selanjutnya digambarkan dalam bentuk kuadran. Selanjutnya dilakukan analisa untuk masing-masing kuadrannya untuk mengidentifikasi tindakan yang perlu dilakukan. Dari hasil penelitian dapat diperoleh simpulan sebagai berikut:

1. Diperoleh nilai indeks kepuasan Peserta JKN Cabang Pati sebesar 88,85 persen.

2. Kemampuan petugas kantor BPJS Kesehatan dalam memberikan kepastian waktu saat aplikasi mengalami kendala menjadi hal yang penting sebagai upaya peningkatan kepuasan Peserta JKN Cabang Pati.

Adapun saran untuk penelitian yang akan datang:

1. Elemen pelayanan tidak hanya pada administrasi kantor, tetapi juga pada elemen pelayanan di tingkat fasilitas kesehatan. Seperti di Fasilitas kesehatan tingkat pertama yang meliputi Dokter Keluarga, Puskesmas dan Klinik. Sedangkan pada Fasilitas kesehatan tingkat lanjutan meliputi Rumah Sakit baik milik Pemerintah maupun Swasta.

2. Wawancara dilakukan dengan lebih mendalam disertai dengan pertanyaan terbuka yang lebih menyeluruh.

\section{Daftar Pustaka}

Kotler, Philip dan Kevin Lane Keller, 2007. Manajemen Pemasaran Edisi Ketiga Belas, Jakarta : PT Indeks

Lupiyoadi, Rambat dan Hamdani, 2006. Manajemen Pemasaran Jasa, Jakarta : Salemba Empat

Mohamad Edris dan Dina L, 2016. Analisis Operasional BPJS Kesehatan Terhadap Prinsip Ekonomi Syariah. University Research Colloquium 2016

Rangkuti, Freddy, 2002. Measuring Customer Satisfaction. Jakarta : Gramedia Pustaka Utama

Rizal Nugraha dkk, 2014. Usulan Peningkatan Kualitas Pelayanan Jasa pada Bengkel "X" Berdasarkan Hasil Matrix Importance-Performance Analysis (Studi Kasus di Bengkel AHASS PD Sumber Motor Karawang. Jurnal Online Institut Teknologi Nasional No 03 Vol 01 
Undang-undang nomor 40 tahun 2004 tentang Sistem Jaminan Sosial Nasional Undang-undang nomor 24 tahun 2011 tentang Badan Penyelenggara Jaminan Sosial http://bpjskesehatancabangklungkung.blogspot.co.id/

http://www.kompasiana.com/infobpjskesehatan/testimoni-peserta-bpjs-kesehatantidak-pernah-ada-iur-biaya-saat-sayakemoterapi 56b2a07e8923bd691d489f2e

http://www.jatengprov.go.id/id/berita-utama/pelayanan-dan-data-peserta-bpjsamburadul

http://www.murianews.com/2016/10/20/98195/bpjs-kesehatan-dikeluhkan-veteranblora.html 